\title{
OS ALFAZETES: UM ABECEDÁRIO GAIATO EM TRADUÇÃO
}

Telma Franco Diniz *

Resumo: No abecedário Os Alfazetes, as letras encenam uma recriação brejeira do Gênesis. Os nomes revelam seus distintos temperamentos: Angry A é colérica, Bashful B é acanhada, e há personagens do gênero feminino, masculino, e indeterminados. Porém, enquanto em inglês os adjetivos são invariáveis, em português a maior parte varia. Como traduzir? Adotar o gênero feminino para todas as personagens, já que são letras? É uma solução, mas escolhê-la significa eliminar a diversidade e camuflar a atração entre duas letras do mesmo gênero, sutilmente sugerida no original. Neste artigo, discuto as soluções para manter a diversidade, em abordagem distinta da edição espanhola, que optou por um elenco todo feminino.

Palavras-chave: Estudos da tradução. Abecedário. Os Alfazetes.

\section{INTRODUÇÃO: ABECEDÁRIOS}

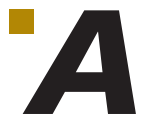

presentar as letras do alfabeto a crianças em fase de alfabetização é um dos propósitos de um abecedário. E os há de todos os tipos: há aqueles que apresentam as letras singelamente, no estilo " $A$ is for Apple", ou "Sou A de Amora"; há os que redesenham as letras, para deixar seu perfil semelhante a um animal cujo nome começa com a letra em questão, como Gone Wild, de David McLimans (2006); os que usam pinturas que tenham algum objeto que comece com a letra estudada, atiçando o espírito detetivesco infantil, como I Spy: An Alphabet in Art, de Lucy Micklethwait (1996); os que se valem de divertidos trava-línguas com predominância da letra a ser aprendida, feito o $A B C$ do trava-língua, de Rosinha (2012); os que criam histó- 
rias tendo as letras por personagens, como Os Alfazetes, de Shirley Glaser (2014a), e inúmeros outros exemplos. Assim, além da "lição das letras" cada um desses diferentes abecedários também veicula outro propósito, aparentemente subordinado ao primeiro, porém tão motivado quanto. Se fizéssemos um estudo dos abecedários ao longo da história, certamente identificaríamos diferentes motivações por parte de autores, ilustradores e editores, no âmbito da época em que viveram. Possivelmente diferentes motivações também por parte dos tradutores e suas escolhas tradutórias.

A título de exemplo, vejamos um abecedário português, lançado recentemente, e dois abecedários brasileiros, lançados com um intervalo de quase 70 anos: Do Brasil, A festa das letras, lançado pela primeira vez em 1937, escrito por Cecília Meireles e Josué de Castro e ilustrado por João Fahrion, e De letra em letra, escrito por Bartolomeu Campos de Queirós e ilustrado por Elisabeth Teixeira, lançado em 2004. De Portugal, Hoje sinto-me... com texto e ilustrações de Madalena Moniz, lançado em 2014.

Em A festa das letras (MEIRELES; CASTRO, 1996), cada letra se apresenta diretamente ao leitor, usando preferencialmente palavras cujas iniciais são a letra em estudo. Cecília, signatária do Manifesto dos Pioneiros da Escola Nova, nas décadas de 1930 e 1940 foi uma das defensoras mais ardentes dos ideais da escola progressiva: pública, laica e gratuita para todos, numa abordagem antroposófica, como sugere ser o abecedário que ela ajudou a criar. Lançado em 1937, A festa das letras integrava a "Série Alimentação", da Editora Globo de Porto Alegre, e visava instruir a então crescente população estudantil sobre questões de higiene, estudos e alimentação. Tomemos como exemplo a letra B, que afirma: "Sou o B da Boca-limpa, sou o B do Banho-frio, sou o B Brincalhão: trago Bife com Bertalha para um Batalhão!” (MEIRELES; CASTRO, 1996, p. 3). Noções de boa alimentação e de higiene são fartas: é preciso tomar banho, mastigar bem os alimentos, escovar os dentes. As letras a que faltam alimentos com suas iniciais para "apadrinhar", como X ou H, passam a divulgar noções de civilidade: H destaca o trabalhador Honesto e Honrado: "Hércules - força que luta e que vence, - Homem Honesto - que pensa e trabalha, esse é o Herói que sai sempre com Honra de qualquer batalha!” (MEIRELES; CASTRO, 1996, p. 16). Demasiadamente didática? Os autores não a consideravam assim, e no prefácio defendiam seu objetivo: "A festa das letras procura ser um pretexto agradável para fazer chegar às crianças, revestidos de certo encantamento, esses primeiros preceitos de higiene alimentar, indispensáveis à sua vida" (MEIRELES; CASTRO, 1996, p. 4).

Tais ideias estavam alinhadas com o "discurso de sanitarização da sociedade, especialmente no tocante às questões de higiene pessoal e social" (CUNHA; BASTOS, 2001, p. 206). Os autores tinham consciência de se dirigirem a uma dupla audiência: à criança, em primeiro lugar, mas também a educadores, professores, pais e avós, que certamente esperavam dos autores essa postura de sanitização educativa.

Já o abecedário De letra em letra, de Bartolomeu Campos de Queirós (2004), à primeira vista parece não ter outro objetivo senão o de ensinar o ABC. Em seus textos curtos, todas as palavras (à exceção de preposições, conjunções e adjuntos) começam com a letra em questão: "Com A, Alice Abraça Ave, Água, Amora. Alice Aprecia Asas e Aves. Adora Azuis e Águas. Ama Amoras e Árvo- 
res” (QUEIRÓS, 2004, p. 4). À medida que viramos as páginas, percebemos que a consciência ecológica e o cuidado com a natureza são temas frequentes: "Com F Fernando Facilita Flor, Fruto, Floresta. Fernando é Filho da Fortuna. É Fruto e Flor Florindo a Floresta" (QUEIRÓS, 2004, p. 9); "Com O Otávio Olha Oceano, Onda, Ostra. O Olhar de Otávio é de Ouro: Ouve a Oração dos Oceanos, o Ondular das Ondas e a Origem das Ostras" (QUEIRÓS, 2004, p. 19). Não há prefácio de autor, mas a Editora Moderna expõe suas ideias e objetivos na quarta capa:

De letra em letra é um texto capaz de levar o leitor a encontrar nos elementos do mundo as palavras que se escrevem com a mesma letra de seu nome [...] os jovens leitores vão se encantar com as possibilidades das palavras e seus muitos sentidos. Assim, ler e escrever passa a ser um prazer (grifo nosso).

Se A festa das letras, lançado na primeira metade do século XX, tentava angariar a simpatia do adulto discorrendo sobre a importância da higiene, da honestidade e da alimentação saudável, De letra em letra, lançado em 2004, flerta com o adulto na quarta capa ao sugerir que os jovens leitores passarão a ter prazer em ler e escrever (como se antes não tivessem?). Além disso, as personagens de suas páginas são sensíveis, preservam o meio ambiente e amam os animais, temas caros aos pais e professores do século XXI.

E quanto ao abecedário da ilustradora portuguesa Madalena Moniz? Publicado em Portugal, em 2014, pela Orfeu Negro, Hoje sinto-me mostra um menino em 26 estados de espírito diferentes (Audaz, Baralhado, Curioso, Distante...), cada um começando com uma letra do alfabeto. Os sentimentos são ilustrados de maneira metafórica, como a própria Madalena Moniz (2015) relata em entrevista ao site Picturebook Makers:

As palavras escolhidas para cada letra são adjetivos que descrevem o estado de espírito do menino e são ilustradas com metáforas e ideias que acrescentam significado à palavra. O objetivo era conseguir criar a relação mais interessante possível entre palavra e imagem.

Além de ensinar as letras, outro propósito do abecedário de Madalena é fazer ver à criança que é possivel que ela em alguns momentos se sinta "distante", "minúscula", "sozinha": hipótese corroborada pelas quatro últimas páginas do livro, com espaço para o leitor responder à pergunta "E tu? Como te sentes?" (MONIZ, 2014, p. 53).

Cada um dos livros aqui mencionados tem particularidades que desafiam a tradução, especialmente por se tratar de abecedários ilustrados. O livro ilustrado, em si, já impõe desafios à tradução, por apresentar "uma relação dinâmica entre palavras e imagens”, conforme alertam Salisbury e Styles (2013, p. 89, grifo nosso):

Na maioria dos casos, as ilustrações funcionam como um acompanhamento visual para as palavras, uma inspiração ou auxílio para a imaginação, com o objetivo de enriquecer a experiência da leitura. Porém, no caso dos livros ilustrados, as palavras e imagens se completam, para dar um significado geral à 
obra. [...] Muitas vezes essa dualidade pode ser na forma de uma dança divertida, onde as imagens e as palavras podem flertar umas com as outras, ou se contradizerem.

O abecedário Hoje sinto-me... pode ser enquadrado no caso em que palavras e imagens se completam ou flertam umas com as outras, o que não diminui a dificuldade de tradução. Vejamos o exemplo da letra Q, que vem exemplificada com o adjetivo "Querido", e ilustrada por dezenas de porta-retratos tendo o menino como o fotografado. Seria "Hoje sinto-me... querido". Numa tradução para o inglês, "querido" poderia corresponder a "loved", "beloved", "workshipped", "treasured", "revered", "precious" e alguns outros adjetivos, nenhum que comece com a letra Q. A saída, então, seria intercambiar as imagens? A letra $\mathrm{Q}$ iria para a imagem do $\mathrm{P}$ - o menino montando um quebra-cabeça que, com o Q, se tornaria Quizzical, e não mais Paciente, como estava - e a imagem dos porta-retratos passaria a ilustrar o P de Precious, por exemplo? Uma saída possivel, que envolve malabarismo por parte do tradutor para intercambiar as imagens com outros adjetivos que também encaixem, ainda que não exatamente a mesma coisa. O tradutor seria então, também, um montador de quebra-cabeças.

Algo semelhante se deu no processo de tradução do abecedário objeto deste artigo, The Alphazeds, lançado em 2003 nos Estados Unidos pelos autores norte-americanos Shirley e Milton Glaser. Mas antes de falar sobre o processo de tradução em si, vejamos o que a editora Gustavo Gili diz sobre os propósitos de Os Alfazetes, na quarta capa da edição brasileira, lançada no Brasil em 2014:

Este livro nos apresenta ao alfabeto e à arte da tipografia de forma totalmente original e divertida. Conheceremos um grupo de letras rebeldes que se encontram pela primeira vez em uma pequena sala amarela. O que será que as levou até ali? Antes de terminar o livro, um segredo extraordinário que mudará o mundo nos será revelado... (GLASER, 2014a, quarta capa, grifo nosso).

"Original" e "divertido" são quase "palavras de ordem" nos dias atuais, em que "rebeldia" também é vista com um viés positivo, de atitude assertiva, de não passividade. Higiene, honestidade e capacidade de trabalho do primeiro abecedário cederam lugar a alegria, diversão, contato com a natureza. Não é o caso de concluir apressadamente que conceitos como caráter e civilidade estejam menos valorizados hoje. Longe disso. Mas é evidente que a agenda escolar e familiar vem sofrendo alterações, e cada época tem seus tópicos mais prementes. Os Alfazetes também tem algo a dizer, além da "lição das letras". Que "segredo extraordinário" seria esse que promete "mudar o mundo"? E até que ponto a dança entre palavras e ilustrações desafiará a tradução?

\section{Os Alfazetes: AUTORES E ENREDO}

O texto de Os Alfazetes é da artista gráfica Shirley Glaser; as ilustrações são de seu marido, Milton Glaser, também artista gráfico, criador do logo da campanha de revitalização de Nova York, "I (heart) NY", reproduzido à exaustão. 
Para compor as personagens-letras, Milton Glaser se inspirou em fontes tipográficas reais ("E" tem feições da Excelsior, "G" da Garamond etc.). Cada uma ganhou uma cor diferente: vermelha, azul, laranja, estampada. Coube a Shirley contar a história dessas personagens, e criar suas personalidades: Angry A, Bashful B, Confused C, Dynamic D, e assim sucessivamente. Um dos diferenciais do abecedário Os Alfazetes, então, é atribuir a cada letra um nome que remete ao estado de espírito predominante naquela personagem - estados de espírito que todos nós podemos sentir, com maior ou menor frequência, dependendo da situação em que nos encontramos. Mas enquanto no abecedário de Madalena Moniz [Hoje sinto-me], um único personagem experimenta 26 estados de espírito diferentes, no abecedário de Shirley Glaser [Os Alfazetes] cada um dos 26 personagens experimenta um único estado de espírito naquele determinado dia em que se encontram.

As falas dos Alfazetes vêm dentro de balões, enquanto a história vai sendo narrada, em frases simples e curtas, na parte inferior da página. Tudo começa numa sala vazia. O Alfazete A é o primeiro a entrar na sala vazia. B vem logo em seguida, e é recebido de maneira um tanto hostil por A: "O que você está fazendo aqui?" (Figura 1).

Figura 1 - Bashful B entra na sala onde Angry A entrara momentos antes

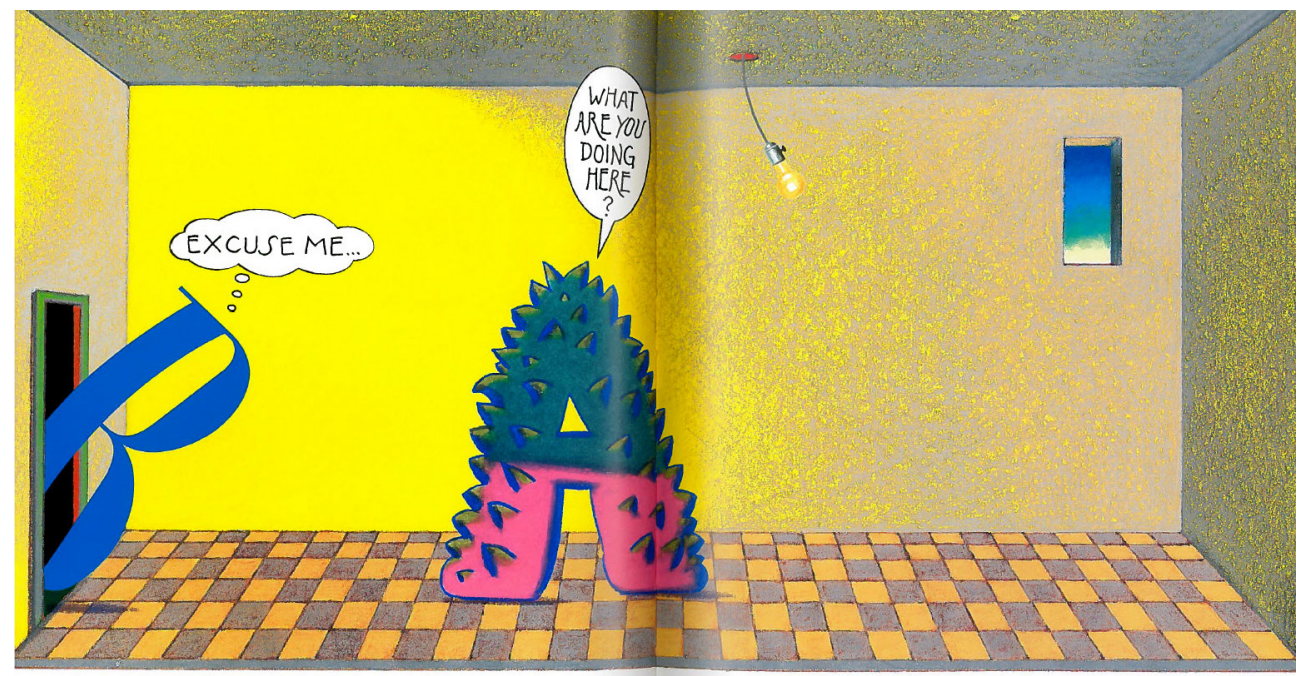

A moment later: A was followed into the room by Bashful B.

Fonte: Glaser (2003).

Uma após a outra, as letras vão chegando e entrando, desfilando suas diferentes cores, estilos, tamanhos e fontes. A sala vai ficando cada vez mais apertada, e a troca de farpas entre as personagens se intensifica. Por fim, o que era um bate-papo entremeado por uma alfinetada aqui, outra acolá, acaba se transformando em discussão, com respostas desaforadas (Figura 2). 
Figura 2 - A sala se enche e as personagens começam a trocar farpas

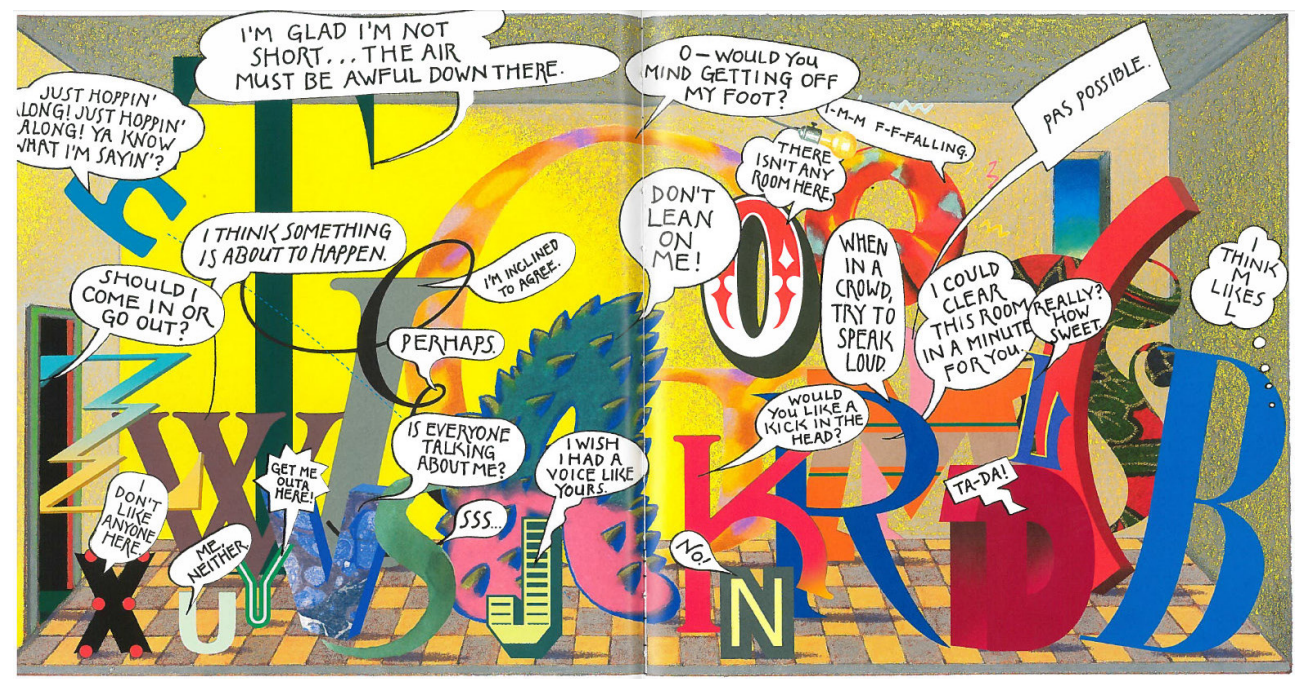

Vain V, Wise IV, Xenophobic X, and Yelling Y all pushed in just before Zigzag Z

always the last to arrive.

Fonte: Glaser (2003).

Todos falam ao mesmo tempo, e arma-se uma grande confusão: "O bate-boca era medonho. Todo mundo gritava a plenos pulmões. Ninguém se importava com ninguém mais. E foi pernada, bofetada, canelada e cotovelada a torto e a direito. Um completo desastre... Mas eis que de repente..." (GLASER, 2014a, p. 25).

A luz se apaga e as trevas enchem a sala. Depois de algum tempo do mais profundo silêncio, ouve-se uma voz: "Faça-se a luz!". A sala se clareia, e as letras W, O, R e D descobrem que, juntas, tinham criado... a escrita! (Figura 3) A narrativa então termina sem caos, com a citação bíblica "In the beginning there was the WORD" (GLASER, 2003, p. 30).

\footnotetext{
"The noise was terrible. Everyone was screaming at the top of their lungs. Nobody cared about anyone else. They were pushing and shoving and hitting and kicking. It was a disaster..." (GLASER, 2003, p. 25).
} 
Figura 3 - As letras aprendem que, juntas, podem fazer parte de algo maior

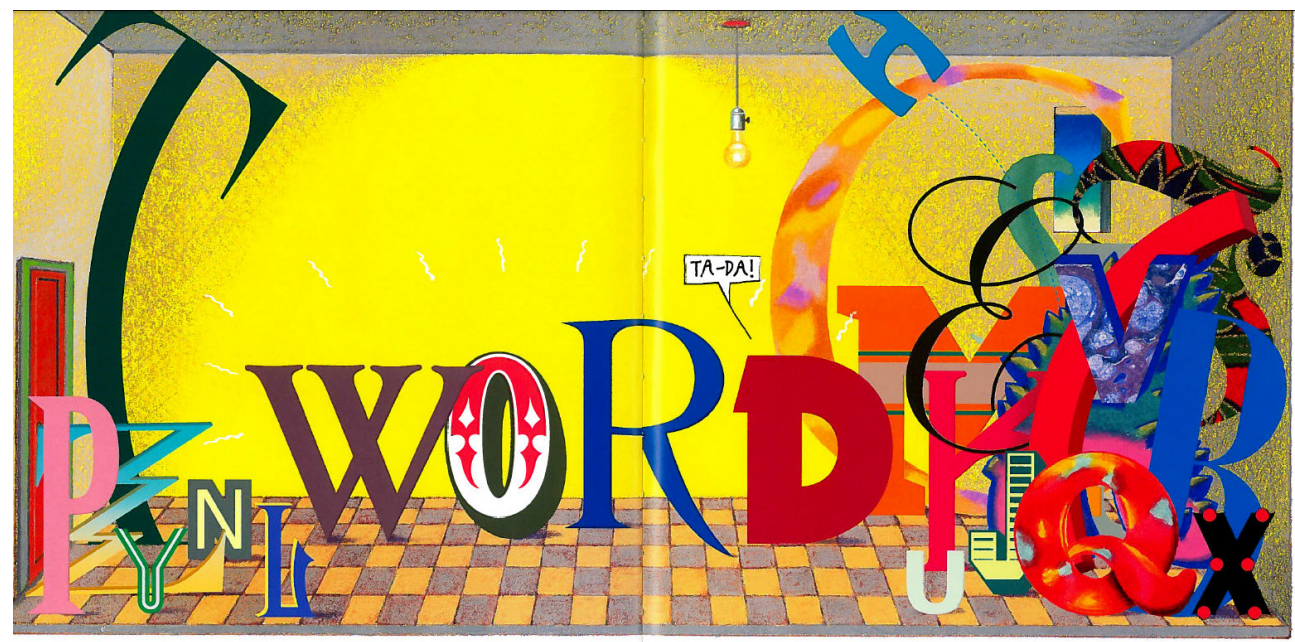

When the light came back on, something extraordinary had happened. Four letters had gotten together to comfort one another. Together they had managed to create something larger and more important than themselves. They had made the first word. At that moment, all the letters suddenly realized their reason for being in the room. It wasn $t$ simply about expressing themselves or showing ofl. They could $\mathrm{be}$ a part of something bigger, something that
and everyone could play an important part.

Fonte: Glaser (2003).

\section{A TRADUÇÃo}

Livros ilustrados têm um "formato polifônico que incorpora muitos códigos, estilos, artificios textuais, referências intertextuais" (HUNT, 2010, p. 128); neles, texto e imagem "funcionam em uníssono", o que faz com que raramente alguma imagem seja alterada na tradução para outra língua (SALISBURY; STYLES, 2013, p. 89). Porém, no caso da imagem aqui reproduzida na Figura 3, manter a ilustração original, em que as letras formam "word", seria incorrer em quebra do uníssono entre a figura (em inglês) e o texto (em português), com consequente perda do sentido ${ }^{2}$. Assim, para a página específica da citação bíblica, a editora criou outra ilustração, substituindo WORD por VERBO: em português, a citação "In the beginning there was the WORD" manteve-se como já consagrada, há séculos, "No princípio era o VERBO". A ilustração com "verbo" serviu também para a edição espanhola, lançada simultaneamente à brasileira: "En el principio fue el VERBO" (GLASER, 2014b, p. 30).

Com isso, parece se revelar outro propósito do abecedário dos Glaser, além da "lição das letras": a celebração da individualidade e diversidade, mas num trabalho coletivo. Cada qual com o seu papel ajudaria a construir algo maior, evitando o caos.

Em qualquer comunidade, membros são parte e são todo ao mesmo tempo, e é preciso levar em conta o coletivo e o individual juntos. $\mathrm{Na}$ "comunidade" a que

2 Uma solução seria acrescentar uma glosa, com o narrador explicando que as letras tinham criado uma palavra em inglês, "word", que poderia ser traduzida como "verbo" em português. 
chamamos "texto", é preciso lidar com os detalhes também, e voltar às outras questões da trama, a começar pela tradução dos nomes dos personagens. O que fazer com os nomes-adjetivos cuja tradução para o português não começa com a mesma inicial, como Bashful B, Jealous J, Kicking K, Mighty M, Quaking Q, Yelling Y? E com Wise W? E Hopping H?

Descartei a ideia de mudar radicalmente a característica (personalidade) da letra e assim "batizá-la" com outro nome (ainda que mantendo as mesmas iniciais do original), pois o comportamento das letras no enredo é reflexo de seus nomes: Bashful B é acanhada e costuma ficar de cabeça baixa; Jealous J nunca está contente com os próprios dotes; Kicking $\mathrm{K}$ dá pontapés a torto e a direito, sem olhar a quem; Mighty M não leva desaforo pra casa; Rhyming R só se comunica em rimas, e assim por diante. A saída desse impasse foi adaptar os nomes das letras para a tradução mais aproximada - isso quando a tradução mais correspondente ao original não fosse possivel. Em suma, recriações.

Detalhes são fundamentais para compor um todo coeso, mas antes de decidir qualquer coisa em relação aos detalhes, é preciso ter uma boa ideia do todo - um procedimento prático comum entre tradutores, como revela Riita Oittinen (2003, p. 129) em artigo sobre tradução de livros ilustrados:

[...] Uma tradução é sempre uma combinação de um todo e suas partes. Os tradutores geralmente partem de uma ideia integral do livro a ser traduzido antes de tomarem qualquer decisão sobre a tradução dos detalhes. Diante de cada detalhe, os tradutores precisam avaliar o modo como ele se ajusta ao resto da história.

É um processo de contínuo vaivém: tomada isoladamente, a tradução de um detalhe pode não fazer muito sentido, mas no contexto do todo, pode mudar de figura; é preciso estar sempre pesando os aportes feitos - o traduzido com o todo, e com o que ainda está por traduzir. Curiosamente, esse vaivém parece emular a história d'Os Alfazetes: por mais que as letras tenham valor per se, é na relação com as outras que elas ganham em importância e significado. Com uma ideia geral do todo, passei a ponderar os detalhes, começando pelos nomes. $\mathrm{Pa}-$ ra visualizar o conjunto e facilitar as escolhas criei o Quadro 1.

Quadro 1 - Original versus traduções versus sugestões de tradução versus final

\begin{tabular}{|l|l|l|l|}
\hline Original & $\begin{array}{l}\text { Traduções } \\
\text { correspondentes }\end{array}$ & $\begin{array}{l}\text { Traduções } \\
\text { aproximadas }\end{array}$ & Decisão \\
\hline Angry $[$ he $]$ & $\begin{array}{l}\text { furioso; colérico; } \\
\text { zangado; irado }\end{array}$ & $\begin{array}{l}\text { antipático; } \\
\text { abusado; arrogante; } \\
\text { agressivo; azedo }\end{array}$ & Azedo [ele] \\
\hline Bashful [he] & $\begin{array}{l}\text { retraído; acanhado; } \\
\text { constrangido; } \\
\text { encabulado }\end{array}$ & $\begin{array}{l}\text { balbuciante; } \\
\text { brando; benigno; } \\
\text { benévolo; bonzinho; } \\
\text { bonachão; borocoxôn }\end{array}$ & Borocoxô [ele] \\
\hline
\end{tabular}


Quadro 1 - Original versus traduções versus sugestões de tradução versus final (continuação)

\begin{tabular}{|c|c|c|c|}
\hline Original & $\begin{array}{l}\text { Traduções } \\
\text { correspondentes }\end{array}$ & $\begin{array}{l}\text { Traduções } \\
\text { aproximadas }\end{array}$ & Decisão \\
\hline Confused [he] & $\begin{array}{l}\text { confuso; perplexo; } \\
\text { desconcertado; } \\
\text { tantã }\end{array}$ & confuso & Confuso [ele] \\
\hline Dynamic [he] & $\begin{array}{l}\text { dinâmico; vibrante; } \\
\text { ativo; energético }\end{array}$ & $\begin{array}{l}\text { dinâmico; } \\
\text { descolado; diligente; } \\
\text { despachado }\end{array}$ & Dinâmico [ele] \\
\hline Elegant [he] & $\begin{array}{l}\text { elegante; distinto; } \\
\text { gentil; refinado }\end{array}$ & $\begin{array}{l}\text { estiloso; elegante; } \\
\text { esbelto; } \\
\text { empedernido }\end{array}$ & $\begin{array}{l}\text { Elegante [bio: ela; } \\
\text { enredo: } \\
\text { indeterminado }\end{array}$ \\
\hline $\begin{array}{l}\text { Flamboyant } \\
{[\text { undetermined] }}\end{array}$ & $\begin{array}{l}\text { espalhafatoso; } \\
\text { extravagante; } \\
\text { vistoso }\end{array}$ & $\begin{array}{l}\text { flamejante; festivo; } \\
\text { fulgurante; } \\
\text { faiscante; faceiro }\end{array}$ & $\begin{array}{l}\text { Flamejante } \\
\text { [indeterminado] }\end{array}$ \\
\hline Gigantic [he] & $\begin{array}{l}\text { gigantesco; } \\
\text { garboso; graúdo }\end{array}$ & $\begin{array}{l}\text { gigantesco; graúdo; } \\
\text { grotesco; garboso }\end{array}$ & Gigantesco [ele] \\
\hline Hopping [he] & saltitante; travesso & hiperativo; hippie & Hiperativo [ele] \\
\hline Italic [she] & itálica; grifada & $\begin{array}{l}\text { inclinada; itálica; } \\
\text { indulgente }\end{array}$ & Itálica [ela] \\
\hline Jealous [she] & $\begin{array}{l}\text { ciumenta; invejosa; } \\
\text { ressentida }\end{array}$ & $\begin{array}{l}\text { jururu; janota; } \\
\text { jabiraca; jararaca }\end{array}$ & $\begin{array}{l}\text { Jururu } \\
\text { [indeterminado] }\end{array}$ \\
\hline Kicking [he] & $\begin{array}{l}\text { chutador; } \\
\text { escoiceador; } \\
\text { espezinhador }\end{array}$ & karateca; kafkiano & $\begin{array}{l}\text { Karateca } \\
\text { [indeterminado] }\end{array}$ \\
\hline Lovely [she] & $\begin{array}{l}\text { adorável; linda; } \\
\text { graciosa; } \\
\text { encantadora }\end{array}$ & $\begin{array}{l}\text { lânguida; linda; } \\
\text { lisérgica; luzente }\end{array}$ & Linda [ela] \\
\hline Mighty [she] & $\begin{array}{l}\text { poderosa; } \\
\text { majestosa; forte; } \\
\text { onipotente }\end{array}$ & $\begin{array}{l}\text { mandona; } \\
\text { mandachuva; } \\
\text { marrenta; maioral }\end{array}$ & $\begin{array}{l}\text { Maioral [bio: ela; } \\
\text { enredo: } \\
\text { indeterminado] }\end{array}$ \\
\hline Negative [he] & $\begin{array}{l}\text { pessimista; } \\
\text { negativo }\end{array}$ & $\begin{array}{l}\text { nojento; neurótico; } \\
\text { negativo }\end{array}$ & Negativo [ele] \\
\hline Ornate [he] & $\begin{array}{l}\text { ornamentado; } \\
\text { adornado; enfeitado }\end{array}$ & $\begin{array}{l}\text { ostensivo; } \\
\text { ornamentado; } \\
\text { orgulhoso }\end{array}$ & Ornamentado [ele] \\
\hline Pretentious [he] & $\begin{array}{l}\text { pretensioso; } \\
\text { presunçoso }\end{array}$ & $\begin{array}{l}\text { pomposo; } \\
\text { pretensioso; prosa; } \\
\text { pedante }\end{array}$ & Pomposo [ele] \\
\hline
\end{tabular}


Quadro 1 - Original versus traduções versus sugestões de tradução versus final (continuação)

\begin{tabular}{|c|c|c|c|}
\hline Original & $\begin{array}{l}\text { Traduções } \\
\text { correspondentes }\end{array}$ & $\begin{array}{l}\text { Traduções } \\
\text { aproximadas }\end{array}$ & Decisão \\
\hline Quaking [he] & $\begin{array}{l}\text { medroso; gago; } \\
\text { vacilante }\end{array}$ & $\begin{array}{l}\text { queixoso; } \\
\text { quimérico; } \\
\text { quixotesco; } \\
\text { qualquer }\end{array}$ & Queixoso [ele] \\
\hline Rhyming [he] & rimador; versejador & $\begin{array}{l}\text { repentista; ritmista; } \\
\text { rimador }\end{array}$ & $\begin{array}{l}\text { Repentista } \\
\text { [indeterminado] }\end{array}$ \\
\hline Sibilant [he] & $\begin{array}{l}\text { sibilante; } \\
\text { sussurrante }\end{array}$ & $\begin{array}{l}\text { sibilante; } \\
\text { sussurrante }\end{array}$ & $\begin{array}{l}\text { Sibilante [bio: ela; } \\
\text { enredo: } \\
\text { indeterminado] }\end{array}$ \\
\hline Towering [he] & $\begin{array}{l}\text { muito alto; } \\
\text { altaneiro; eminente }\end{array}$ & $\begin{array}{l}\text { topetudo; tremendo; } \\
\text { titânico }\end{array}$ & Topetuda [ela] \\
\hline Unimportant [he] & $\begin{array}{l}\text { desprezível; trivial; } \\
\text { insignificante; } \\
\text { banal }\end{array}$ & $\begin{array}{l}\text { ulterior; último; uó; } \\
\text { ultrapassado; } \\
\text { ultrajado }\end{array}$ & Ultrapassado [ele] \\
\hline Vain [she] & vaidosa; fútil; inútil & $\begin{array}{l}\text { vão; vaidoso; } \\
\text { volúvel }\end{array}$ & Vaidosa [ela] \\
\hline Wise [he] & $\begin{array}{l}\text { sábio; sensato; } \\
\text { prudente; perspicaz }\end{array}$ & $\begin{array}{l}\text { workaholic; } \\
\text { wikipédico }\end{array}$ & Wikipédica [ela] \\
\hline Xenophobic $[$ she $]$ & xenófoba & xenófoba & Xenófoba [ela] \\
\hline Yelling [he] & $\begin{array}{l}\text { berrador; gritalhão; } \\
\text { vociferante }\end{array}$ & $\begin{array}{l}\text { yuppie; yanomami; } \\
\text { yankee; yakuza }\end{array}$ & $\begin{array}{l}\text { Yanomami } \\
\text { [indeterminado] }\end{array}$ \\
\hline Zigzag [he] & $\begin{array}{l}\text { zigue-zague; } \\
\text { sinuoso; } \\
\text { ziguezagueante }\end{array}$ & $\begin{array}{l}\text { zureta; zonzo; } \\
\text { ziguezagueante }\end{array}$ & $\begin{array}{l}\text { Ziguezagueante } \\
\text { [ela] }\end{array}$ \\
\hline
\end{tabular}

Fonte: Elaborado pela autora.

Na primeira coluna do Quadro 1, temos o nome da letra em inglês; na segunda, a(s) tradução(ões) mais aproximada(s); na terceira, traduções não muito próximas, mas possiveis, usando qualificativos com a inicial apropriada e procurando seguir o "espírito da letra" e da obra como um todo; por fim, na quarta coluna, a tradução adotada.

Algo de que tratarei mais adiante, e que envolveu muita reflexão, foi a questão do gênero. No original, as letras não são todas do mesmo gênero, há letras no masculino (no Quadro 1, marquei-as com o pronome "he"), há letras no feminino (pronome "she"), e há algumas que não deixam transparecer o gênero (para as quais usei a etiqueta "undetermined"). Veremos isso no tópico "A questão dos gêneros".

O Quadro 1 mostra minhas opções para todas as letras, mas nem todas foram problemáticas. Assim, na discussão sobre o processo de tradução, tratarei apenas daquelas que, por apresentarem algum desafio tradutório, exigiram maior desvelo de minha parte: as letras A; B; F; H; K; M; R; W; Y. 
Traduzir Bashful B foi um dos grandes dilemas; a meu ver, as traduções mais imediatas para "bashful" são "acanhado" e "encabulado", que não começam com B. Uma ideia seria Balbuciante - começa com B, sugere alguém tímido, dentro do escopo de Bashful. Porém, quase todas as "falas" de B usavam balões estilo "nuvem", que são símbolo para "pensamentos", não "falas". Se B quase nunca fala, não faz sentido dizer que ele balbucia. Então me ocorreu um adjetivo que significa "abatido", "desanimado", e tem sonoridade divertida: Bo-ro-co-xô. É bom lembrar que textos infantis muitas vezes são lidos em voz alta pelo adulto para a criança, especialmente na faixa etária a que são destinados os abecedários, que é a de leitores iniciantes: "Em caso de livros para serem lidos em voz alta, como em geral são os livros infantis ilustrados, espera-se que o tradutor facilite ao máximo a tarefa de quem os lerá. Para ser lido em voz alta, um texto deve fluir na língua do leitor" (OITTINEN, 2003, p. 129) 3 .

A fluência da leitura em voz alta é favorecida por palavras graciosamente sonoras, e "Borocoxô" atende a esses requisitos. A partir dessa constatação, para ficar no registro leve e informal e manter certa unidade de conjunto (o chamado "todo coeso"), segui na esteira do B Borocoxô onde possivel: eu havia cogitado traduzir "Angry A", que se compraz em espezinhar as outras letras, por "A Agressivo" - uma tradução correta, mas convencional. Acabei optando por "A Azedo", dentro da ideia de manter um "paradigma brincalhão", corroborando a hipótese de que tradução de livro ilustrado é um processo de contínuo vaivém.

Os pioneiros "A Azedo" e "B Borocoxô" abriram caminho para opções menos convencionais para o restante do elenco. Pretentious $\mathrm{P}$, que só fala em francês e poderia ser P Pretensioso, tornou-se P Pomposo. Já Rhyming R, que só se comunica por versos rimados e poderia ser R Rimadora, assume a brasilidade: vira $R$ Repentista. Na sala lotada, "This is a squeeze that does not please", pronunciado por Rhyming R torna-se "Não gosto de amasso quando é por falta de espaço" na voz da R Repentista. Flamboyant F, deveras luxuriante, torna-se F Flamejante; e Towering $\mathrm{T}$, muito alta e gabola, $\mathrm{T}$ Topetuda.

Afastei-me um pouco mais da literalidade nas letras J, K, Q e Y por não encontrar nenhum correspondente próximo o suficiente. A invejosa Jealous J, que demonstra desejar ser (ou ter) o que as outras letras são (ou têm), tornou-se J Jururu (acabrunhada). Kicking K, que abre caminho a pontapés, virou K Karateca; e já que um dos motes dos autores é a celebração da diversidade, K Karateca entra na sala contando "um, dois, três, quatro" em japonês, como se marchasse, "Ichi, ni, san, shil", como sabe toda criança que faz artes marciais no Brasil. Quaking Q, que titubeia ao falar, virou Q Queixoso. E Yelling Y? Palavras começadas com $Y$ em português ocupam apenas meia página do dicionário Houaiss. No original, Yelling Y só fala aos gritos. Minhas opções dicionarizadas eram yankee, yuppie, yakuza e yanomami. Em nome da inocência infantil e da herança indígena brasileira, adotei Y Yanomami. A casa editora aprovou.

Hopping H usa bordões ditos por rappers como "ya know what I'm sayin", dança break e salta pra lá e pra cá, fazendo de H Hiperativo uma opção natural. Para dar verossimilhança às falas desse fã de hip-hop, ouvi entrevistas de MV Bill e Mano Brown e pincei algumas de suas expressões mais frequentes. Assim, tra-

3 "In case of books to be read aloud, like children's picture books usually, the translator is supposed to make the aloud-reader's task as easy as possible. The text to be read aloud must roll on the aloud-reader's tongue." 
duzi "Ya know what I'm saying?" como "Tá ligado?”. Já a expressão "Just hoppin' along! Ya know what I'm sayin?" ficou "Hip hop na veia! Sem vacilo, tá ligado?”

\section{A guestão dos GÊneros}

É sabido que não há flexão de gênero para adjetivos na lingua inglesa, diferentemente da portuguesa, em que a flexão de gênero ocorre com frequência. Não é o caso, porém, dos adjetivos "borocoxô" e "elegante", usados para o gênero masculino ou feminino sem alterações, mas é o caso de um enorme contigente de adjetivos como "azedo", "confuso", "gigantesco" e "hiperativo", para ficar em alguns Alfazetes, e que, assim flexionados, referem-se a personagens do gênero masculino.

Contudo, a falta de flexão em inglês não impede que se identifique o gênero das letras por outros meios. No desenrolar do enredo de The Alphazeds (GLASER, 2003), é possivel determinar o gênero de três personagens-letras porque há menção a "he" ou "him" nas conversas entre elas. Sabemos que Gigantic G é menino porque a legenda da página $15 \mathrm{diz}$ "Gigantic G squeezed in as Hopping $H$ hip-hopped over him", que traduzi como "Enquanto G Gigantesco entrava encolhido, sobre ele saltava H Hiperativo". Angry A também é menino porque quando Elegant E pergunta a Bashful B "Are you in any way related to A?", que eu traduzi como "Você tem algum parentesco com A?", Bashful B responde: "I just followed him", ou seja, "Eu apenas o segui até aqui". E quando Gigantic G pergunta a Kicking K "Por que você chutou H?" ["Why did you kick H?"], Kicking K responde: "He bugs me" [Ele me irrita].

Os leitores conheceriam apenas o gênero das personagens $\mathrm{G}, \mathrm{H}$ e A se Os Alfazetes terminassem onde termina o enredo. Embora a história termine na citação "No princípio era o VERBO", a obra em si continua no Apêndice, intitulado "Quem é quem no elenco", o que sugere que as letras são atores e atrizes participando de uma encenação do Gênesis. "Quem é quem no elenco" traz pequenas biografias de nossas figuras letradas, com destaque para seus feitos: papéis marcantes; filmes, peças ou séries de TV em que atuaram; livros que escreveram; filmes que dirigiram; canções que interpretaram; indicações de prêmios e títulos recebidos; carreiras paralelas à de atores/atrizes, entre outros fatos interessantes.

Escritas em fonte miúda, em cor preta sobre fundo branco, as biografias fazem referência a eventos e títulos reais - por exemplo, a premiação do Oscar, a canção "Yesterday" dos Beatles, a peça The Iceman Cometh, de Eugene O'Neil, a revista Vogue -, provocando o riso em leitores adultos, ou com conhecimento suficiente para inferir as intertextualidades. Tais biografias talvez não despertem o interesse do leitor em formação, em fase de alfabetização - público preferencial da história que envolve os Alfazetes - mas certamente diverte a outra instância leitora: pais, mediadores, professores.

Além disso, os textos de "Quem é quem" usam preferencialmente palavras que comecem com a inicial da personagem biografada. Na biografia de Lovely L, por exemplo, lê-se: "Lovely L played the lyrical, luminous lead in Lady Luck"4, que recriei como " $L$ Linda foi louvada pela luminosa atuação na versão lirica de $A$ vida intima de Laura, de Lispector". A biografia de Sibilant S diz: "Sibilant S starred as

4 Tradução literal: "L Linda interpretou a luminosa e lírica protagonista de Lady Luck". 
Simon in The Seventh Step, for which he scribbled the screenplay as well"5, que recriei como "S Sibilante obteve surpreendente sucesso com o samba Sassaricando. Seu solilóquio Soneto de Separação precipitou sua seleção para viver a soprano felina na sátira Os Saltimbancos". Nesses dois exemplos, os textos das biografias em inglês revelam o gênero das personagens. Lovely L é "she" e Sibilant $\mathrm{S}$, "he" (um dos que tornei "ela" na versão em português). Mas nem todas as biografias deixam transparecer o gênero do(a) biografado(a). É o caso de Flamboyant F, cuja biografia informa que "F Flamboyant appeared in Flag, Father, and fortyfive performances of Fifty-something". Eu a recriei de maneira a manter a indeterminação, lançando mão do pronome obliquo "lhe": "F Flamejante estreou como figurinista da farsa Sr. Funga-Funga. Sua feliz figuração no espetáculo de fantoches Um baú de fundo fundo proporcionou-lhe uma legião de fãs fascinados". No Quadro 1, usei "undetermined/indeterminado" para as personagens cujo gênero permanece incógnito no enredo e na biodata, como é o caso de F Flamejante.

E por que essa questão é importante?

$\mathrm{Na}$ introdução deste artigo, discutimos o fato de abecedários terem outros propósitos além de ensinar a "lição das letras", e Os Alfazetes não são exceção. Com tantos personagens diferentes entre si, tanto na aparência quanto na personalidade, outro de seus propósitos é a defesa da diversidade. No entanto, ao averiguar as biografias do elenco em busca do gênero de cada letra, notei que The Alphazeds em inglês não é tão equilibrado nem tão diversificado no quesito gênero: das 26 letras do alfabeto, 19 são do gênero masculino [A, B, C, D, E, G, $\mathrm{H}, \mathrm{K}, \mathrm{N}, \mathrm{O}, \mathrm{P}, \mathrm{Q}, \mathrm{R}, \mathrm{S}, \mathrm{T}, \mathrm{U}, \mathrm{W}, \mathrm{Y}, \mathrm{Z}]$; seis são do feminino [I, J, L, M, V, X]; e uma [Flamboyant F] é "genderless". Esta última é "indeterminada" por não haver menção a pronome ou outra marca que identifique seu gênero, seja na narrativa, seja na biografia. No entanto, em se tratando da narrativa da história em si, podemos dizer que há um aparente equilíbrio entre os gêneros, porque apenas três letras são identificadas como do gênero masculino - as outras 23 ficam indeterminadas, já que os adjetivos em inglês não flexionam em gênero. Isso nos faz pensar que, devido à indeterminação, as crianças leitoras do original (que supostamente lerão somente a narrativa, sem interesse nas biografias), não perceberão nenhum desequilíbrio entre os gêneros. Já os leitores da versão em português perceberiam um enorme desequilíbrio entre os gêneros, se todas as 19 letras que aparecem como gênero masculino em inglês fossem traduzidas como tais (lembrando que em português os adjetivos flexionam). No caso, a "celebração da diversidade" que, a meu ver, é um dos propósitos de Alphazeds, ficaria seriamente prejudicada em português.

Por isso, no processo de tradução para o português, deliberadamente reduzi o contingente de letras do gênero masculino e ampliei o número de letras do gênero feminino e das sem gênero ou de gênero indeterminado. Assim, na tradução, temos 11 letras do gênero masculino [A, B, C, D, G, H, N, O, P, Q, U], dez do gênero feminino [ $\mathrm{E}, \mathrm{I}, \mathrm{L}, \mathrm{M}, \mathrm{S}, \mathrm{T}, \mathrm{V}, \mathrm{W}, \mathrm{X}, \mathrm{Z}$ ] e cinco de gênero indeterminado $[\mathrm{F}, \mathrm{J}, \mathrm{K}, \mathrm{R}, \mathrm{Y}]$. Para tê-las em "gênero indeterminado", escolhi nomeá-las com adjetivos uniformes, que não variam quanto ao gênero, ou com substantivos comuns de dois, tomando o cuidado de não mencionar pronomes ou outra marca reveladora do gênero.

5 Tradução literal: "S Sibilante estrelou, como Simon, The Seventh Step, cujo roteiro ele também escreveu". 
Essa estratégia foi especialmente importante na tradução de Mighty M, que entabula uma conversa com Lovely L. A personagem Bashful B está por perto e entreouve o diálogo. Ao perceber que $\mathrm{M}$ se insinua para L, B Borocoxô pensa com seus botões: "Eu acho que M gostou de L" (GLASER, 2014a, p. 25).

$\mathrm{Na}$ narrativa original, sabe-se que Lovely L é "menina", mas nada é revelado sobre o gênero de Mighty M. Apenas na biografia Mighty M aparecerá como do gênero feminino também. Os leitores que se limitarem a ler apenas a narrativa na obra original, sem recorrer às biografias, talvez não percebam que a atração entre M e L se dá entre duas letras do mesmo gênero. Para manter a sutileza do subtexto na tradução, escolhi traduzir Mighty por Maioral, substantivo comum de dois, evitando usar o artigo definido para não indicar o gênero. Assim, a atração fica apenas sutilmente sugerida, como fez a autora Shirley Glaser no original em inglês. Mas aqueles que lerem as biodatas (tanto em inglês quanto em português) certamente perceberão a sugestão - o que, acredito, era o intuito dos Glaser.

O lançamento d'Os Alfazetes no Brasil ocorreu simultaneamente ao lançamento de Las Alfazetas, na Espanha. Talvez por questões de praticidade, já que "letra" é substantivo feminino em espanhol também, o tradutor espanhol preferiu recriar todas as personagens no gênero feminino, o que é uma solução válida. Preferi não adotá-la, pois um dos meus objetivos, como tradutora, era preservar a diversidade sugerida no original.

\section{“TRADUZiNDo" gUem É gUem NO ELENCO}

Se a recriação da parte narrativa de Os Alfazetes proporcionou desafios e diversão, que dirá a recriação do Apêndice "Quem é quem no elenco". Os textos das biodatas originais foram costurados com inúmeras referências à cultura ocidental contemporânea, especialmente à cultura norte-americana, com menções a canções, obras e autores famosos, assim como também a obras desconhecidas do grande público, mas reconhecidas por uma minoria bem informada. Entre as referências mais famosas, destaco a peça The Iceman Cometh, de Eugene O'Neil, que aparece na biodata de "Italic I": "Italic I was involved as the ill-fortuned Ivy in O'Neil's The Iceman Cometh". A referência à cantiga infantil "Jack and Jill" na biodata de Jealous J também está entre as mais populares: "Jealous J played Jill in the jazz version of Jack and Jill". Dentre as referências pouco conhecidas, há por exemplo a peça The Seventh Step, de 1954, do autor irlandês Padraic Fallon, mais popular na Irlanda. Também desconhecida do público mundial, mas famosa entre nova-iorquinos, é a festa dançante Rhythm Revue, irradiada ao vivo por uma FM de Nova York desde 1986, e mencionada na biodata de Rhyming R: "Rhyming $R$ is a regular rapper on the Rhythm Revue Radio Show".

"Quem é quem no elenco" foi claramente elaborado para divertir a segunda instância leitora de The Alphazeds: os adutos. Em vista disso e tendo em conta que o original faz algumas referências específicas a Nova York, mais conhecidas do público local, a editora Gustavo Gili liberou a recriação total das biodatas, desde que se mantivesse a estratégia de escrevê-las usando palavras cuja inicial fosse a inicial em questão, ou seja: privilegiar palavras começadas com A para

6 "I think M likes L" (GLASER, 2003, p. 25). 
recriar a biodata do A Azedo, com B para recriar a do B Borocoxô, e assim sucessivamente. A tradução das biodatas, por isso, mais se assemelha a uma adaptação que a uma tradução. A biodata da Confused C, por exemplo, que em inglês é "Confused C received a Drama Desk Award for his part in Cactus Circus", em português ficou " $C$ Confuso ainda é celebrado pela verve cômica no curta Carimbador maluco, contemplado com o Troféu Calunga". A referência à peça "Cactus Circus" foi substituída pela referência à música Carimbador maluco, de Raul Seixas, e o prêmio Drama Desk foi substituído pelo troféu pernambucano Calunga, entregue anualmente aos premiados do Festival do Audiovisual do Recife.

A Figura 4 apresenta outros exemplos de recriação de biodatas, com muitas referências a espetáculos e criações brasileiras e algumas internacionais.

Figura 4 - Recorte de "Quem é quem no elenco", biodatas de Os Alfazetes

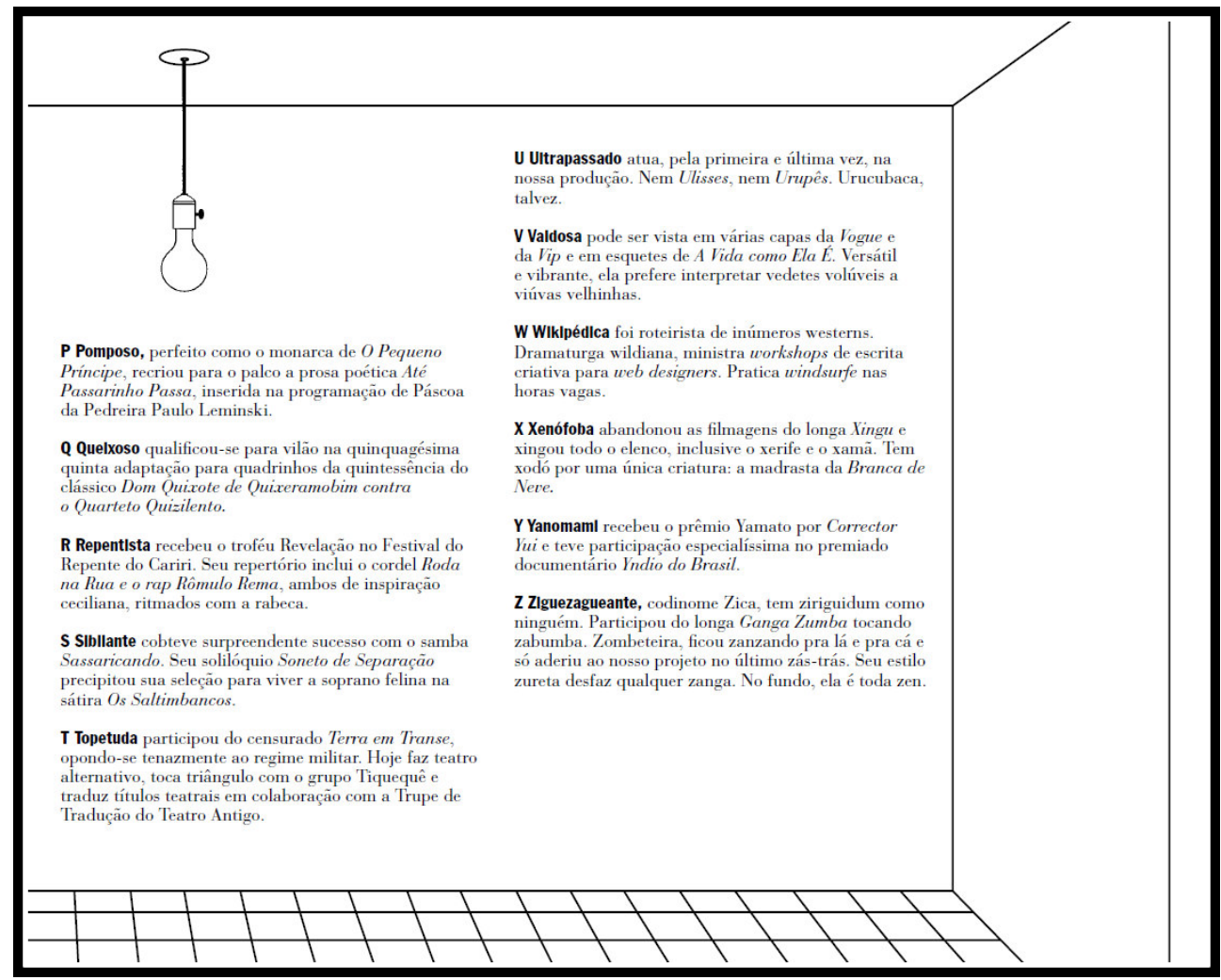

Fonte: Glaser (2014a).

\section{CONSIDERAÇÕES FINAIS}

É certo que ilustrações podem ajudar o tradutor em sua tarefa, evidenciando, por exemplo, a aparência de algo - como a postura intorvertida do personagem Bashful B, sempre cabisbaixo, caracteristica que me ajudou a lembrar do adje- 
tivo "borocoxô", e a nomear Bashful B como B Borocoxô. Mas as ilustrações também podem representar um enorme desafio, já que, por causa dos direitos autorais e de outras questões, as imagens de um livro ilustrado dificilmente são alteradas no processo de tradução (OITTINEN, 2003, p. 133). Há exceções, como visto no caso d'Os Alfazetes, tratado aqui, em que uma das ilustrações foi alterada por se tratar de citação bíblica consagrada pelo uso. De qualquer maneira, o tradutor de livros ilustrados se vê diante do dilema de harmonizar texto e imagem num todo coeso: o que conta é a história contada por ambos.

Um livro infantil ilustrado também envolve leitura em voz alta, outro desafio que o tradutor não pode deixar de levar em conta. Há quem compare a leitura em voz alta de um livro infantil a um espetáculo teatral: quem lê em voz alta "interpreta" o texto para a criança ouvinte (OITTINEN, 2003, p. 132). Ao recriar o texto, o tradutor tem de considerar seu ritmo, o comprimento de suas frases, suas respiração, suas pausas... Transformar um período longo em dois curtos pode alterar sobremaneira o efeito poético ou dramático que o autor imprimiu à passagem no original. E vice-versa. Várias frases em sequência sem pausa ou vírgula podem provocar no leitor a sensação de perseguição e coração acelerado se a história for um thriller. Esse mesmo recurso de períodos longos sem vírgulas ou pausas também pode ser eficiente em provocar um transbordamento de emoções ou até mesmo certa sensação de transcendência se o intuito for deixar o leitor sem fôlego, como um balão que sobe e se perde no céu.

Sustentei, neste estudo, que abecedários têm dupla audiência. Como visto, Os Alfazetes não é exceção, e mantém a tradição de visar a dupla instância leitora, como faz a melhor parte dos livros ditos "infantis". A seção "Quem é quem no elenco", colocada despretensiosamente no fim do livro como se fosse um apêndice, visa claramente o público adulto: a fonte pequenina não atrai o olhar das crianças, talvez até mesmo iniba sua leitura, o que sugere que ela não foi pensada para crianças, mas para seus mediadores, sejam eles pais, professores, avós. As múltiplas referências a peças, filmes, livros e shows em que Os Alfazetes atuaram ao longo de sua fictícia vida artística, reforçam a hipótese de que as biodatas foram escritas para adultos. Como público em formação, poucas crianças talvez tenham maturidade ou conhecimentos culturais suficientes para ler nas entrelinhas e apreciar o currículo dos "artistas" ali elencados. Uma hipótese que eu preferiria ver desmentida.

Sustentei também que abecedários têm ao menos duas agendas: uma declarada, explícita - ensinar o $\mathrm{ABC}$ - e outra nem sempre declarada, mais sutil, muitas vezes implícita, entesourando algum ideal do autor - por exemplo, zelar pelo meio ambiente. No que concerne os propósitos declarados, vimos que os autores d'Os Alfazetes desejam apresentar o leitor "ao alfabeto e à arte da tipografia de forma totalmente original e divertida", e, ao fazerem isso, também apresentam ao leitor um elenco de personagens com temperamentos, cores, estilos e gêneros diferentes. Apesar das diferenças, esses personagens aprendem a se relacionar e a produzir "algo maior", o que nos faz crer que esta seria a agenda implícita dos autores: motivar o leitor à tolerância, à solidariedade, a celebrar a diversidade.

O tradutor deve ficar atento à agenda implícita para atuar junto com ela. Ou não. Em qualquer dos casos, a escolha deve ser feita de maneira consciente. $\mathrm{Na}$ introdução desse artigo, afirmei que "se fizéssemos um estudo dos abecedários 
ao longo da história, certamente identificariamos diferentes motivações por parte de autores, ilustradores e editores, no âmbito da época em que viveram, e possivelmente diferentes motivações também por parte dos tradutores". Exatamente. Neste artigo, procurei demonstrar que a tradução que fiz de Os Alfazetes foi motivada: aliei-me aos propósitos implícitos que julguei ter visto no original dos Glaser - o de celebrar a coletividade e uma diversidade ampla e geral, tanto de cores, quanto de vestimentas, de falas, de personalidades, de gênero, de orientação sexual - e cuidei para preservá-los.

Acredita-se que traduções de livros infantis são as mais afeitas a adaptações por serem destinadas a um público em formação - crianças e jovens que ainda não têm capital cultural suficiente para apreender ideias e referências da cultura-fonte por não estarem familiarizados com ela. No caso do livro em estudo, porém, é interessante notar que as adaptações mais profundas foram realizadas na seção "Quem é quem no elenco", para agradar a segunda instância leitora, os adultos, que leem em voz alta o livro para a criança.

Livros infantis ilustrados, felizmente, nunca cansam de nos surpreender.

\section{The Alphazeds: a Jesting ABC in translation}

Abstract: The Alphazeds is a sassy re-creation of the Genesis, in which the characters are the letters of the alphabet. Their names reveal their different personalities: Angry A, Bashful B, Confused C and so on. Gender differs too: characters are male, female, or undetermined. But while in English adjectives do not alter their form to reflect gender, in Portuguese most often they do. Making all letters female (since in Portuguese "letter" is a feminine noun) would flatten gender diversity and camouflage the attraction between two letters of the same sex or gender, subtly implied in the original work. In this article, I discuss the solutions I came upon in order to keep gender diversity, an approach somewhat different from the one adopted by the Spanish translator, who worked with an all-female cast.

Keywords: Translation studies. ABC books. The Alphazeds.

\section{REFERÊNCIAS}

CUNHA, M. T.; BASTOS, M. H. Letras em festa. In: NEVES, M. (Org.). Cecília Meireles: a poética da educação. Rio de Janeiro: Loyola, 2001.

GLASER, S. The Alphazeds. Ilustração Milton Glaser. Singapore: Disney-Hyperion, 2003.

GLASER, S. Os Alfazetes. Ilustração Milton Glaser. São Paulo: Gustavo Gili, $2014 a$.

GLASER, S. Las Alfazetas. Ilustração Milton Glaser. Tradução Alvaro Marcos. Barcelona: Gustavo Gili, 2014b.

HUNT, P. Understanding children's literature. New York: Routledge, 2010.

MCLIMANS, D. Gone Wild. New York: Walker \& Company, 2006. 
MEIRELES, C.; CASTRO, J. de. A festa das letras. Ilustração João Fahrion. Rio de Janeiro: Nova Fronteira, 1996.

MICKLETHWAIT, L. I Spy: An Alphabet in Art. New York: Greenwillow Books, 1996.

MONIZ, M. Hoje sinto-me... Lisboa: Orfeu Negro, 2014.

MONIZ, M. Hoje sinto-me... de A a $Z$ : entrevista concedida ao blog Picturebook Makers. 9 junho de 2015. Disponivel em: <http://blog.picturebookmakers. com/post/121106566946/madalena-moniz>. Acesso em: 19 fev. 2016.

OITTINEN, R. Where the wild things are: translating picture books. Meta: Translators' Journal, Montreal, v. 48, n. 1-2, p. 128-141, 2003.

QUEIRÓS, B. C. de. De letra em letra. Ilustração Elisabeth Teixeira. São Paulo: Moderna, 2004.

ROSINHA. ABC do trava-lingua. São Paulo: Editora do Brasil, 2012.

SALISBURY, M.; STYLES, M. Livro infantil ilustrado: a arte da narrativa visual. Tradução Marcos Capano. São Paulo: Rosari, 2013.

Recebido em agosto de 2017. Aprovado em setembro de 2017. 